\title{
Degradation in an Inert Solid Medium of Poly(Lactic Acid) Polymeric Material by Kibdelosporangium aridum
}

\author{
Alain Copinet $\cdot$ Estelle Copinet-Legin • \\ Florence Fricoteaux • Damien Erre
}

Published online: 14 December 2010

(C) The Author(s) 2010. This article is published with open access at Springerlink.com

\begin{abstract}
The aim of this work was to estimate the biodegradation of a poly(lactic acid) polymeric material by the actinomycetes Kibdelosporangium aridum using a vermiculite based inert solid medium which could simulate compost medium and enable us to achieve complete carbon balances. The mineralisation rate at the end of the test was compared to those obtained for two basal media. It was shown that cumulative mineralisation after 45 days of degradation was greater $(70 \%)$ in vermiculite with a basal medium containing gelatin than in vermiculite with a basal medium containing glucose $(20 \%)$.
\end{abstract}

Keywords Degradation - Carbon balance vermiculite polyester · Poly(l-lactide) - Kibdelosporangium aridum

\section{Introduction}

Due to environmental concern caused by plastic storage, degradable polymers are of growing interest as an alternative to traditional degradation-resistant petrol-based polymers. In terms of polymer compostability, degradation is assessed as the proportion of carbon originally present in the polymer that is converted into carbon dioxide, but generally disregards the proportion of material remaining

\footnotetext{
A. Copinet $(\varangle) \cdot$ F. Fricoteaux $\cdot$ D. Erre

GRESPI (Groupe De Recherche en Sciences Pour l'Ingénieur), Esplanade Roland Garros, Pôle Technologique Henri Farman, BP1029, Cedex 2, 51686 Reims, France

e-mail: alain.copinet@univ-reims.fr

E. Copinet-Legin

LMI (laboratoire de Microbiologie Industrielle), Moulin de la

Housse, 51686 Reims, Germany

e-mail: estelle.copinet@univ-reims.fr
}

in the medium or transformed into biomass. As compost is a very complex medium, containing various chemical compounds and biological species, determination of a complete polymer degradation carbon balance is practically impossible. Likewise, determining the role of each biological species in the compost during polymer biodegradation is extremely difficult.

Recently, some researchers have introduced novel degradation tests based on an inert mineral solid medium [1] to deal with the problems and restrictions inherent to degradation tests in compost. These kinds of supports were used to reach enhanced repeatability, to avoid priming effects [2] or for quantitative and qualitative recovery of potential toxic by-products released during the degradation process. In a previous study, we developed a model compost medium based on the use of an inert solid medium composed of vermiculite [3] that allows for the accurate determination of the complete carbon balance [4]. Several authors have reported that microbial degradation of PLA is facilitated by actinomycetes of the genus Amycolatopsis [5-9], whereas others have found that actinomycetes play an important role in polyester degradation [10]. In this work, we use Kibdelosporangium aridum as the sole strain to gain additional information on the microorganisms involved in the biodegradation of PLA. Particular attention was paid to the evolution of some physico-chemical properties of the non degraded PLA material, and determination of the PLA degradation carbon balance.

\section{Materials and Methods}

PLA pellets were purchased from Cargill Dow. Before carrying out the degradation tests, the pellets were cooled in liquid nitrogen and crushed into powder in two stages 
(first with a 1-mm sieve, followed by a second grinding with a $0.5 \mathrm{~mm}$ sieve) using a rotor crusher (Retsch ZM 1000). The powdered PLA had a glass transition temperature of $61{ }^{\circ} \mathrm{C}$ and number-average molecular weight, Mw $195.4 \times 10^{3} \mathrm{~g} \mathrm{~mol}^{-1}$.

\section{Microorganisms and Culture Media}

Kibdelosporangium aridum (Japan Collection of Microorganisms, ATCC 39323) was grown on basal medium containing (per liter) $100 \mathrm{mg}$ yeast extract, $200 \mathrm{mg} \mathrm{MgSO}_{4}$. $7 \mathrm{H}_{2} \mathrm{O}, 100 \mathrm{mg} \mathrm{NaCl}, 20 \mathrm{mg} \mathrm{CaCl}{ }_{2} \cdot 2 \mathrm{H}_{2} \mathrm{O}, 10 \mathrm{mg} \mathrm{FeS}-$ $\mathrm{O}_{4} \cdot \mathrm{H}_{2} \mathrm{O}, 0.5 \mathrm{mg} \mathrm{Na} \mathrm{MoO}_{4} \cdot 2 \mathrm{H}_{2} \mathrm{O}, 0.5 \mathrm{mg} \mathrm{Na} \mathrm{WO}_{4} \cdot 2 \mathrm{H}_{2} \mathrm{O}$,

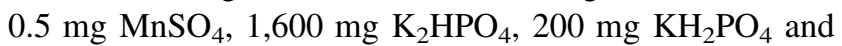
$1,000 \mathrm{mg}(\mathrm{NH} 4)_{2} \mathrm{SO} 4(\mathrm{pH} 7.1)$.

\section{Equipment}

Our automated degradation test bench consists in ten 2-L glass bioreactors (CMF 100, Chemap, Switzerland). The temperature was controlled by double-wall water flow. The airflow in the reactors was adjusted to $0.56 \mathrm{~L} \mathrm{~min}^{-1}$ by a rotary ball meter KAG 1398 (Brooks instruments, Veenendaal, The Netherlands) and is CO2-free thanks to an online CO2 remover (CO2RP140, Domnick Hunter, USA). This allowed the maintenance of aerobic conditions and permitted assessment of the percentage of $\mathrm{CO} 2$ produced (scale $0-2 \%$ ). Gas flow was measured by a mass flowmeter $(5850 \mathrm{Tr}$, Brooks instruments, Veenendaal, The Netherlands). $\mathrm{CO}_{2}$ emissions from the bioreactors were measured automatically every other hour by an infrared gas analyser (Binos $120 \mathrm{M}$, Rosemount, France). An automated acquisition system (Allen-Bradley, Millwaukee, Wisconsin) was used to transfer data to a computer (Rsview 32, Rockwell Software, Velizy-Villacoublay, France). The final quantity of $\mathrm{CO}_{2}$ produced was calculated by integrating the $\mathrm{CO}_{2} \%$ and the gas flow for the sampling time (12 min).

\section{Degradation Test Parameters}

Each bioreactor is composed of a bed of vermiculite ( $180 \mathrm{~g}$ Vermiculite, Grade No. 3; Sigma-Aldrich), $315 \mathrm{ml}$ of mineral solution, $110 \mathrm{ml}$ of culture media of Kibdelosporangium aridum. The mineral solution is buffered at $\mathrm{pH}=7.1$ with $0.1 \%(\mathrm{w} / \mathrm{v})$ glucose (Test \#1) $0.1 \%$ gelatin (Difco) (Test \#2). Tests were initiated by adding $15.5 \mathrm{~g}$ of PLA, containing approximately $7.7 \mathrm{~g}$ of carbon, to the reactor. Each reactor was shaken every other day and the test temperature was maintained at $58{ }^{\circ} \mathrm{C}$. The degradation tests were conducted in triplicate and were monitored for 45 days. Although $\mathrm{CO}_{2}$ was removed from the air entering each reactor, an empty "blank" reactor was included to determine the quantity of carbon dioxide present in the inlet air flow.

\section{Samples Analysis}

The protocol for extraction of the degradation by-products and carbon quantification is summarised in Fig. 1 [11]. Starting with a frozen sample, two $4 \mathrm{~g}$ samples were dried at $105{ }^{\circ} \mathrm{C}$ for dry wet determination. One $4 \mathrm{~g}$ sample was then homogenised in $30 \mathrm{ml}$ of Ringer solution for $40 \mathrm{~min}$. After centrifugation at $10,000 \mathrm{rpm}$ for $20 \mathrm{~min}$, the supernatant was filtered and submitted to dissolved organic carbon (DOC) analysis. The residue (R) was dried in an oven for 2 days, weighed for dry weight determination, was and then ground and submitted to elemental analysis (TOC 5000 Shimadzu). The second $4 \mathrm{~g}$ sample was placed in a known volume of $\mathrm{NaOH}$ solution $(0.025 \mathrm{M})$ and homogenised in an oven at $70{ }^{\circ} \mathrm{C}$ for $48 \mathrm{~h}$. As a result, the ester bonds of the residual PLA were totally broken, releasing lactic acid into the solution. This solution was filtered and the lactic acid content determined using HPLC. HPLC analyses were carried out using an Aminex HPX $87 \mathrm{H}$ column, $300 \times 7.8 \mathrm{~mm}$ (Bio-Rad, Ivry/Seine, France) maintained at $35{ }^{\circ} \mathrm{C}$. The mobile phase $(0.02 \mathrm{~mol} / \mathrm{L}$ sulfuric acid) was degassed by passing through a $0.2 \mathrm{~mm}$ pore size filter and a flow rate of $0.6 \mathrm{~mL} / \mathrm{min}$ was maintained at 900 psi pressure. Lactic acid was measured using a UV detector (TSP 8880, Les Ulis, France). The injection volume of sample was $20 \mathrm{~mL}$. Prior to injection, the samples were filtered through $0.22 \mu \mathrm{m}$ pore size filters (Millipore Corporation, USA). Three filtered solutions corresponding to three replicated experiments were combined. A calibration curve was established beforehand using different

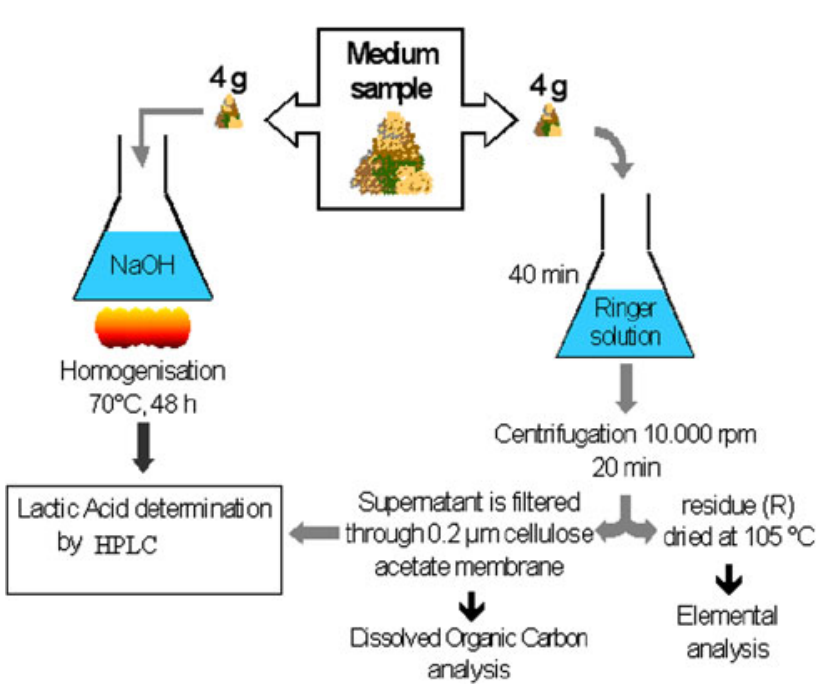

Fig. 1 Protocol for by-products extraction and carbon quantification. [11] 
concentrations of lactic acid (Sigma Chemical Co., Saint Louis, Missouri).

\section{Carbon Balance}

The carbon balance for the degradation of PLA can be established as follows:

$\mathrm{C}_{\text {polymer }}=\mathrm{C}_{\mathrm{b}}+\mathrm{C}_{\mathrm{g}}+\mathrm{C}_{\mathrm{d}}+\mathrm{C}_{\mathrm{nd}}$

where the polymer carbon (Cpolymer) is converted by micro-organisms into biomass carbon $(\mathrm{Cb})$, carbon dioxide $(\mathrm{Cg})$, water soluble by-products $(\mathrm{Cd})$, and polymer carbon which is not yet degraded (Cnd). Carbon dioxide was determined by infrared gas analyser; water soluble degradation by-products were quantified by DOC analysis of the Ringer solution supernatant; and the remaining nondegraded polymer was determined by electrophoresis analysis after complete hydrolysis of the PLA in the $\mathrm{NaOH}$ solution. The lactic acid concentration was considered to be equal to that of original constitutive units with a molecular weight of $72 \mathrm{~g} / \mathrm{mol}$ of the nondegraded PLA (carbon content $=49.97 \%$ ). The amount of carbon contained in the biomass $\left(\mathrm{C}_{\mathrm{b}}\right)$ and non-degraded PLA $\left(\mathrm{C}_{\mathrm{nd}}\right)$ was determined from the elemental analysis of the residue (R). Total residual carbon (CR) is equal to the sum of the polymer carbon converted to biomass $(\mathrm{Cb})$ plus the non-degraded PLA (Cnd); therefore the biomass carbon was calculated as:

$\mathrm{C}_{\mathrm{b}}=\mathrm{C}_{\mathrm{R}}-\mathrm{C}_{\mathrm{nd}}$.

Extraction and Analysis of the Non-degraded PLA Material

For each test, we performed extractions of the non-degraded PLA material in order to follow the change in molecular weight and glass transition temperature. We proceeded as follows: $4 \mathrm{~g}$ of frozen sample were homogenised in $30 \mathrm{~mL}$ of Ringer solution for $40 \mathrm{~min}$ to eliminate soluble by-products (the homegeneization time was kept sufficiently short to avoid chain scission by hydrolysis). The solution was then filtered through a cellulose acetate membrane (porosity: $0.2 \mu \mathrm{m}$ ) and the solid phase dried at $60{ }^{\circ} \mathrm{C}$ until the weight remained stable (this drying step was performed at low temperature to avoid any thermal degradation). The residue was then placed in $30 \mathrm{~mL}$ of chloroform for $10 \mathrm{~min}$ to dissolve any PLA remaining in the sample, centrifuged at $10,000 \mathrm{rpm}$ for $20 \mathrm{~min}$ to remove the bulk of the mineral medium. The supernatant was placed in a syringe and filtered $(0.2 \mu \mathrm{m}$, Millipore, USA) for solvent casting in a Petri dish. After solvent evaporation, the recovered PLA was used for Size
Exclusion chromatography and Scanning Calorimetry determinations.

Physico-chemical Analysis of Remaining PLA Material

Gel permeation chromatography (GPC) testing of PLA film samples was performed using a Thermo Separate products model 300 (les Ulis, France) high-performance liquid chromatography. Tetrahydrofuran (THF) was pumped at $1 \mathrm{ml} / \mathrm{min}$ and an injection volume of $200 \mu \mathrm{L}$ was used for HPSEC analysis. A PLA sample of $0.1 \mathrm{~g}$ was dissolved in $5 \mathrm{ml}$ of THF. A refractive index detector (Shodex RI 71) was interfaced to PIII personal computer. A PL Caliber logiciel and interface PL-DCU (Polymer Laboratories) enabled chromatograms to be numerically recorded. The Plgel $5 \mu \mathrm{m}$ MIXTE-C column (Polymer Laboratories) was used. A molecular weight calibration curve was constructed based on ten narrow-molecular weight-distribution polystyrene standards (Easical), with $\mathrm{Mw}$ peaks ranging from 580 to $7,500,000 \mathrm{gmol}^{-1}$ DSC analysis were performed on a TA-Instruments M-DSC apparatus (USA) with approximately $12 \mathrm{mg}$ of PLA. First, the sample was equilibrated at $0{ }^{\circ} \mathrm{C}$ for $3 \mathrm{~min}$, heated $\left(10{ }^{\circ} \mathrm{C} / \mathrm{min}\right)$ and stabilised at $180{ }^{\circ} \mathrm{C}$ for $2 \mathrm{~min}$. Then the sample was cooled to $0{ }^{\circ} \mathrm{C}$ at $20{ }^{\circ} \mathrm{C} / \mathrm{min}$ and maintained at this temperature for $5 \mathrm{~min}$. The final step was a heating ramp at $10{ }^{\circ} \mathrm{C} / \mathrm{min}$ to a temperature of $200{ }^{\circ} \mathrm{C}$ followed by a return to room temperature. The glass transition temperature was determined in the second heating step.

\section{Results and Discussion}

Figure 2 shows the mineralization curve for PLA degradation in the inert solid medium for Test \#1 [liquid basal medium with $0.1 \%$ (w/v) glucose]. The cumulative mineralization $(\mathrm{Cg})$ after 45 days of degradation totaled about $14 \%$ and the carbon degraded reached about $20 \%$. In order to enhance the inert solid medium mineralization curves, we modified the biochemical parameters of the medium changing the composition of basal medium and replacing glucose with gelatin. As a result, the cumulative mineralization obtained after 45 days was $60 \%$ and degradation was about $70 \%$ (Fig. 3). We also observed a larger decrease in the Mw of the residual PLA during Test \#2 than Test \#1 (Fig. 4). Indeed, the Mw decreased by $18 \%$ in Test $\# 1$ (i.e., from $195.4 \times 10^{3}$ to $160 \times 10^{3} \mathrm{~g} \mathrm{~mol}^{-1}$ ), and by $87 \%$ (i.e. to $25 \times 10^{3} \mathrm{~g} \mathrm{~mol}^{-1}$ ) during Test \#2. During the first 10 days of the test exposures, water-soluble degradation products are to slow to be released, but then increase significantly (Figs. 2, 3). This effect was more pronounced during Test \#2, peaking at about $17 \%$ of the total polymer$\mathrm{C}$ (Fig. 3) against $2.6 \%$ during, Test \#1 and corresponded 


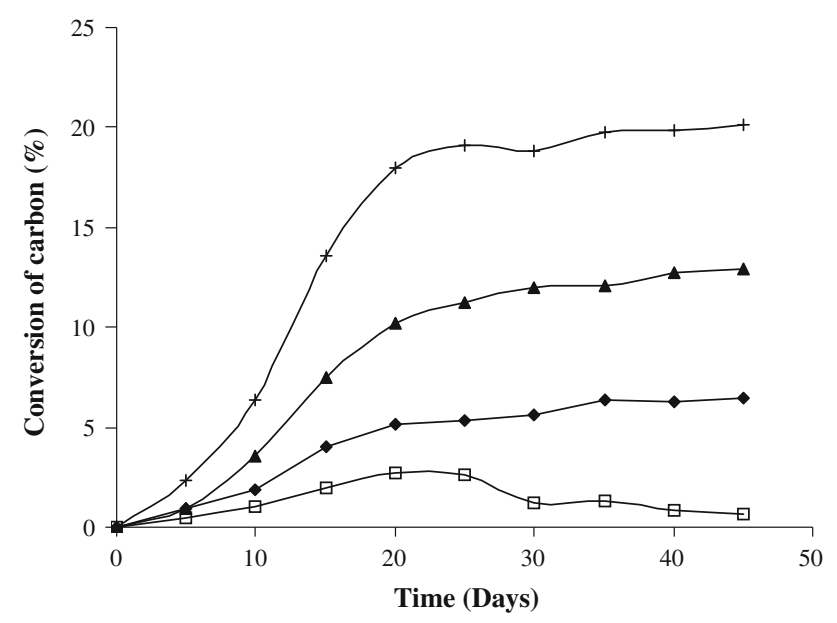

Fig. 2 Carbon balance during the degradation of PLA on vermiculite using liquid culture containing $0.1 \%(\mathrm{w} / \mathrm{v})$ glucose. Carbon soluble (Cs : open square), Carbon dioxide ( $\mathrm{Cg}:$ filled traingle), biomass ( $\mathrm{Cb}:$ filled diamond) Carbon degraded (Cd : plus symbol)

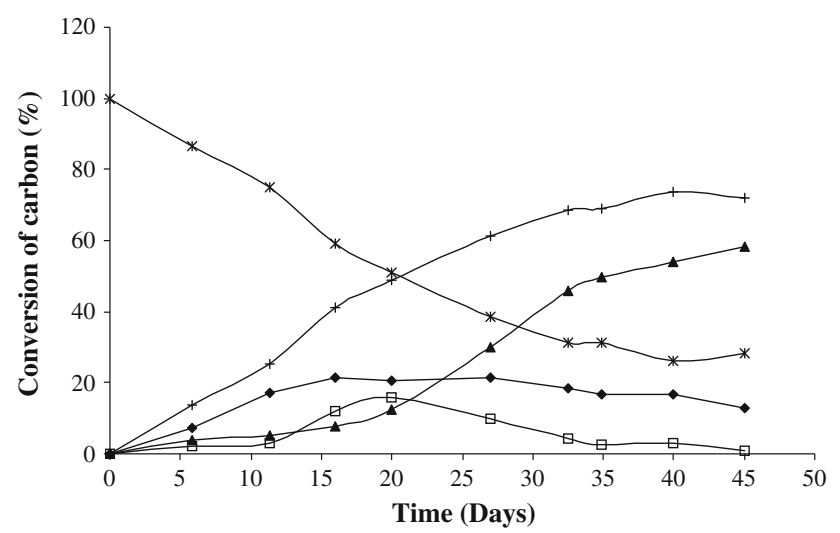

Fig. 3 Carbon balance during the degradation of PLA on vermiculite using liquid culture containing $0.1 \%(\mathrm{w} / \mathrm{v})$ gelatin. Carbon soluble (Cs : open square), No degraded carbon (Cnd : Asterisk), Carbon dioxide ( $\mathrm{Cg}:$ filled triangle), biomass ( $\mathrm{Cb}:$ filled diamond), Carbon degraded (Cd : plus symbol)

to a decrease in molecular weight of the residual PLA (Fig. 4). Soluble, low molecular weight oligomers released into the degradation medium from the polymer matrix via microbial hydrolysis are subsequently used by the microorganisms, leading to the production of additional carbon dioxide and new biomass. Consequently, the water-soluble carbon pool also decreases.

Biomass production $(\mathrm{Cb})$ peaked at about $21 \%$ during Test \#2 (Fig. 3), versus only 5.6\% during Test \#1 (Fig. 2). During the degradation tests, biomass production exhibited a lag period of about 6-10 days, followed by a 10-14 days period of rapid increase, after which biomass production slowed considerably. Following the lag period, during which time the micro-organisms become adapted to the medium, the period of rapid biomass production most

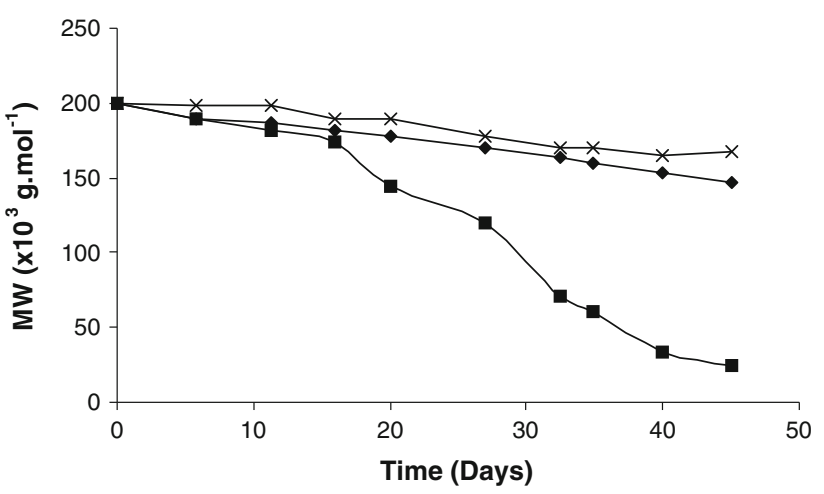

Fig. 4 Change in the Mw of the residual PLA during degradation on vermiculite using liquid culture containing $0.1 \%(\mathrm{w} / \mathrm{v})$ gelatin (filled square), on vermiculite using liquid culture containing $0.1 \%(\mathrm{w} / \mathrm{v})$ glucose (filled diamond), and in the uninoculated control (times symbol)

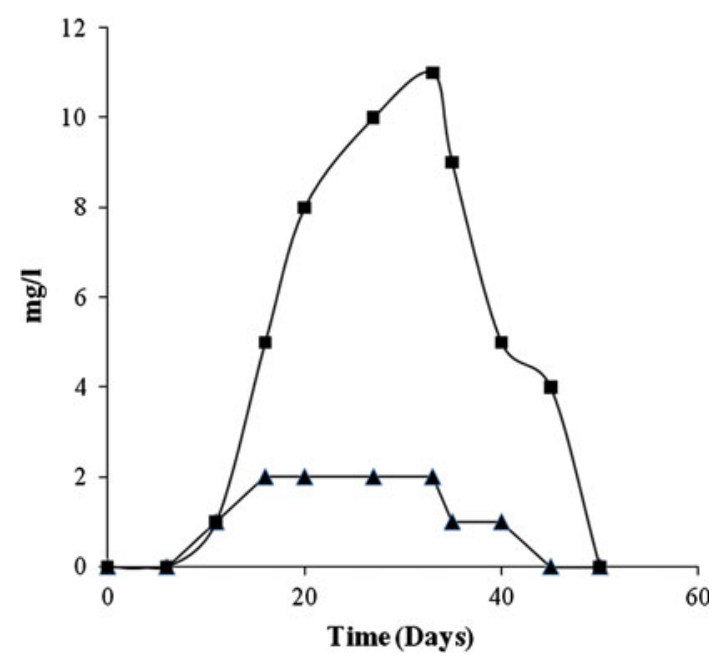

Fig. 5 Lactic released during Test $\neq 1$ (filled triangle) and Test $\neq 2$ (filled square)

likely reflects degradation of short PLA oligomers produced during sample preparation (i.e. grinding) and which are immediately available to the micro-organisms-corresponding to an increase in lactic acid released into the medium (Fig. 5).

The chain scission indicated by the SEC data also has some consequences on the evolution of glass transition temperature. During Test \#2, the Tg decreased from $61{ }^{\circ} \mathrm{C}$ to approximately $58{ }^{\circ} \mathrm{C}$ at Day 10 . This would result in enhanced water absorption in the polymer matrix and, in turn, promote the biotic chain scission reaction and the diffusion of soluble, PLA oligomers into the degradation medium. A similar decrease in Tg was not observed during Test \#1 because abiotic degradation was too weak.

The value of carbon balance for the degradation of PLA for the test \#1 is about $44 \%( \pm 8)$ and $103 \%( \pm 9)$ for test: \#2. The standard deviations are of in inaccuracies added by 
every measures. On the other hand the difference of degradation can explain by difference of production of enzymes which can cut the PLA and what it would be interesting to characterize.

\section{Conclusion}

The utilization of vermiculite as an inert solid support for degradation testing allowed us to thoroughly investigate the degradation process of PLA. A carbon balance was developed, and though the total of carbon recovered was not exactly equal to $100 \%$, the accuracy of the method was sufficient. The utilization of an inert solid medium allowed us to emphasize the biotic degradation of PLA in a solid medium. In this respect, major modifications did not involve the extraction protocol but rather the degradation medium itself, notably the composition of liquid basal medium. With regard to biodegradation in different media, total mineralization for the PLA material on an inert solid with basal medium containing $0.1 \%(\mathrm{w} / \mathrm{v})$ glucose (Test \#1) was $20 \%$; degradation with a basal medium containing $0.1 \%$ (w/v) gelatin (Test \#2) totalled 70\%. Based on these values, we concluded that Kibdelosporangium aridum was capable of biodegrading these PLA materials in the basal medium used for Test \#2. These results indicate that this assay can be used to compare the biodegradation of PLA by different microorganisms. That is, we can gain a better understanding of polymer biodegradation by comparing the different terms of the carbon balance and by analysing the basal medium for the enzyme(s) involved in biodegradation.

Open Access This article is distributed under the terms of the Creative Commons Attribution Noncommercial License which permits any noncommercial use, distribution, and reproduction in any medium, provided the original author(s) and source are credited.

\section{References}

1. Tosin M, Degli-Innocenti F, Bastioli CJ (1998) Polym Degrad 6:79

2. Shen j, Bartha JR (1996) Appl Polym Sci 62:1428

3. Gattin R, Copinet A, Bertrand C, Couturier Y (2001) J Polym Environ 9:11

4. Longieras A, Copinet A, Bureau G, Tighzert L (2003) Polym Degrad Stab 83:187

5. Pranamuda H, Tokiwa Y, Tanaka Polylactide H (1997) Appl Environ Microbiol 63:1637

6. Pranamuda H, Tokiwa Y (1999) Biotechnol Lett 21:901

7. Tokiwa Y, Konno M (1999) H. Nishida Chem Lett 5:355

8. Ikura Y, Kudo T (1999) J Gen Appl Microbiol 45:247

9. Nakamura K, Tomita T, Abe N, Kamio Y (2001) Appl Environ Microbiol 67:345

10. Tokiwa Y, Pranamuda H (2001) Microbial. In: Doi Y, Steinbuchel A (eds) Biopolymers, vol 3. Wiley-VCH, Weinheim, pp 85-103

11. Copinet A, Legin-Copinet E, Erre D (2009) Materials 2:749 